\title{
Congratulations from the ASPE
}

\author{
American Society for Precision Engineering, Past President
}

Drew Devitt

It is with great appreciation that we congratulate the JSPE on its 75th anniversary. Great appreciation because the JSPE was an important inspiration for the founding of ASPE, and an interested JSPE member provided the founding funds for our Society. Because the story behind this is indicative of the open and stimulating collaboration that we have had with the JSPE, we would like to share it with you here.

Shorty after the JSPE's 50th anniversary, Dr. Arthur Diness of the United States Office of Naval Research (ONR) spent some time in ONR's Tokyo office. There he noticed the influence of the JSPE, and the fact that there were departments of Precision Engineering in twenty-five Japanese technical universities. When he returned to the U.S., he campaigned for the establishment of such departments in the U.S., and set up a program to establish Precision Engineering centers here.

Dr. Diness also sent Ray McClure (one of the ASPE founding members) to the Tokyo ONR as a visiting scholar from Lawrence Livermore National Laboratory (LLNL). Before Ray left for Japan, he contacted a Japanese colleague he had met at a CIRP meeting, Professor Akira Kobayashi, from Saitama University.

When Ray arrived in Japan, Prof. Kobayashi immediately took him under his wing, and to a JSPE Conference in Niigata. Ray was the only American there. Sitting through the papers, taking notes (which was fairly easy because almost all of the slide captions were in English) he was noticed. At the reception, Prof. Kobayashi literally lined people up to meet him, resulting in many gracious invitations. Over the next five months he visited more than 45 universities, companies and government labs (in about equal numbers) and traveled Japan from North to South and East to West.

Late in his stay he asked Prof. Kobayashi if he could join JSPE. Shortly thereafter he was invited to meet the JSPE Board of Directors at the Seiko guest house. They approved of his joining. Later, Prof. Kobayashi presented the JSPE Board's desire to have a joint Japanese/American conference. With the help of Prof. Thomas Dow, the conference was arranged and held in Raleigh, North Carolina, at North Carolina State University. It was at this Raleigh meeting that the ASPE organizing committee was formed.

Prof. Toshio Kasai was Prof. Kobayashi's colleague at Saitama. Prof. Kobayashi had sent him to work for a few weeks at LLNL, and to tour the U.S. before attending the Raleigh meeting. The University of California had presented Kasai an honorarium of $\$ 500$ for his visit to LLNL. Upon learning that the ASPE organizing committee had been formed, Kasai donated the honorarium check to the cause. These were the first funds deposited into the new bank account of the American Society for Precision Engineering.

Since these events, cooperation between our societies has led to many stimulating technical collaborations and personal friendships. We look forward to many more. We congratulate you on your 75 years and thank you for your help in the establishment of the ASPE. 